\section{PKS}

PUBLIC

KNOWLEDGE

PROJECT

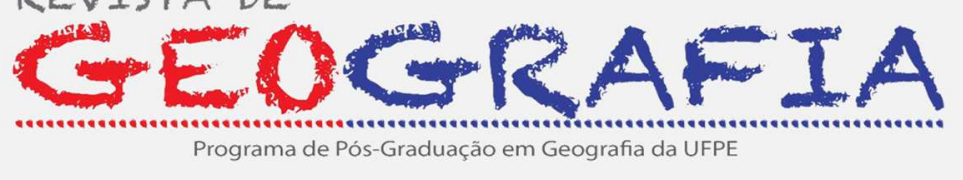

https://periodicos.ufpe.br/revistas/revistageografia
OJS

OPEN

JOURNAL

SYSTEMS

\title{
INTERFERÊNCIA DO TURISMO NA PESCA ARTESANAL: UMA ABORDAGEM DA OCEANOGRAFIA SOCIOAMBIENTAL NO SUDESTE DO BRASIL
}

\author{
Juliana Silva de Abreu ${ }^{1}$, Rafael Granvilla Oliveira ${ }^{2}$, Camilah Antunes Zappes ${ }^{3}$
}

\begin{abstract}
${ }^{1}$ Programa de Pós-Graduação em Geografia, Grupo de Pesquisa em Ecologia Humana e Conservação de Recursos Naturais e Culturais, Instituto de Ciências da Sociedade e Desenvolvimento Regional, Universidade Federal Fluminense. E-mail: juliana.silva.abreu.br@gmail.com, ORCID iD: https://orcid.org/0000-0001-7895-5497.

${ }^{2}$ Secretaria de Estado do Turismo (SETUR), Governo do estado do Espírito Santo, Grupo de Pesquisa em Ecologia Humana e Conservação de Recursos Naturais e Culturais. E-mail: rafaelgranvilla@yahoo.com.br, ORCID iD: https://orcid.org/0000-0002-3506-1909.

${ }^{3}$ Programa de Pós-Graduação em Geografia, Grupo de Pesquisa em Ecologia Humana e Conservação de Recursos Naturais e Culturais, Instituto de Ciências da Sociedade e Desenvolvimento Regional, Universidade Federal Fluminense. E-mail: camilahaz@yahoo.com.br, ORCID iD: https://orcid.org/0000-0002-5486-6577.
\end{abstract}

Artigo recebido em 16/06/2020 e aceito em 01/03/2021

\section{RESUMO}

O objetivo deste estudo é descrever a percepção de pescadores artesanais do município de Guarapari, Espírito Santo em relação à interferência do turismo de pesca esportiva e mergulho sobre a pesca artesanal. Entrevistas etnográficas foram realizadas com 80 pescadores artesanais por meio de questionário semi-estruturado, e sendo aplicados os métodos de observações participante e direta, e uso do diário de campo. Para a análise foram aplicadas as técnicas de Análise de Discurso e Triangulação e estatística descritiva básica. Todos os entrevistados são homens com idade entre 27 e 77 anos e com baixa escolaridade. Dentre os entrevistados, 56 (70\%) atuam como guia de turismo informal junto aos turistas de pesca esportiva e mergulho. Na percepção dos entrevistados $(n=37 ; 46,2 \%)$ o turismo de pesca esportiva e mergulho interfere negativamente na atividade, em que justificam que há uma sobreposição de uso de área entre pescadores e turistas/excursionistas. Tal cenário indica a instabilidade financeira da pesca artesanal e a necessidade de ações de gestão social a fim de garantir a prática da atividade e do turismo de pesca esportiva e mergulho na região.

Palavras-chave: Pesca artesanal. Pesca esportiva e mergulho. Interferência do turismo. Sudeste do Brasil.

\section{INTERFERENCE OF THE TOURISM ON ARTISANAL FISHING: A SOCIAL AND ENVIRONMENTAL OCEANOGRAPHY APPROACH IN SOUTHEASTERN BRAZIL}

\begin{abstract}
The objective this study is describe the perception of artisanal fishers of Guarapari, Espírito Santo regarding the interference of sport fishing and diving tourism on artisanal fishing. Ethnographic interviews were conducted with 80 artisanal fishers through semi-structured questionnaire, using participant and direct observation methods and a field diary. For the analysis were used Discourse Analysis and Triangulation as well as basic descriptive statistics. All the interviewees are men between 27 and 77 years old with low schooling. Among the respondents, 56 (70\%) work as informal tourism guide with sport fishing and diving tourists. According the interviewees $(n=37 ; 46.2 \%)$ the sport
\end{abstract}


fishing and diving tourism negatively interferes on the fishing, and justify that there is an overlap of area use between fishers and tourists / excursionists. This scenario indicates the financial instability of artisanal fishing and the need for social management actions in order to ensure the practice of activity and tourism of sport fishing and diving in the region.

Keywords: Artisanal fishing. Sport fishing and diving. Tourism interference; Southeastern Brazil.

\section{INTRODUÇÃO}

Turismo é um fenômeno social, cultural e econômico em que pessoas saem temporariamente do seu local de residência (MILLER, 1993). Este fenômeno interfere na economia, no ambiente, na cultura local e nos próprios visitantes, que podem ser denominados como turistas ou excursionistas (MILLER, 1993). O turista é o visitante temporário que pernoitou na cidade de destino permanecendo por no máximo 12 meses sem exercer função remunerada (IRTS, 2008). Já o excursionista é o visitante de determinado local que pernoita em outro (IRTS, 2008).

Atualmente, milhares de pessoas praticam o turismo de mergulho recreativo cujo objetivo é vivenciar momentos de lazer na observação e interação com a fauna, flora e geologia marinha (ROWE e SANTOS, 2016). De acordo com a Organização Mundial do Turismo (OMT) esta atividade apresenta intenso crescimento proporcionando riscos ao ambiente e à prática da pesca artesanal (WORLD TOURISM ORGANIZATION, 2007). Junto ao mergulho recreativo, a pesca esportiva é uma atividade também em crescimento definida no Brasil como aquela pesca "praticada por brasileiro ou estrangeiro, com equipamentos ou petrechos previstos em legislação específica, tendo por finalidade o lazer ou o desporto" (LEI FEDERAL n ${ }^{\circ} 11.959 / 2009$ Art. $8^{\circ}$, Seção I). Nesta modalidade é proibido o transporte e comercialização do produto pescado (MILLER, 1993; WORLD TOURISM ORGANIZATION, 2007). Apesar do desenvolvimento destas atividades contribuírem para o lazer na vida das pessoas a prática delas deve ocorrer de forma que não prejudique o ambiente e comunidades locais (MILLER, 1993).

Em todo o mundo o turismo de pesca esportiva e mergulho têm aumentado promovendo uma disputa de espaço entre seus praticantes e pescadores artesanais locais (FAUKENBERRY et al., 2000). Alguns exemplos destes conflitos ocorrem nos Estados Unidos, Chile, Peru, Moçambique e Zâmbia onde o aumento do turismo de pesca esportiva e mergulho criam obstáculos de acesso às áreas tradicionais de pesca artesanal pelas comunidades locais, sobreexploração do recurso pesqueiro, além da destruição do ambiente costeiro (FAUKENBERRY et al., 2000). No Brasil, especificamente nas regiões norte (estado do Pará), nordeste (estado do Rio Grande do Norte) e sul (estado de Santa Catarina) a prática do turismo de pesca esportiva e mergulho também 
é preocupante já que sobrepõe às áreas de pesca artesanal e sobreexplora os recursos interferindo negativamente na vida de comunidades que dependem da pesca (SANTOS e ARANTES, 2010).

No estado do Espírito Santo (ES), sudeste do Brasil está localizado o município de Guarapari $\left(20^{\circ} 38^{\prime} \mathrm{S}-40^{\circ} 27^{\prime} \mathrm{O}\right)$ um dos principais polos atrativos de turistas e excursionistas em busca de atividades de lazer como pesca esportiva e mergulho (IOTMG, 2005). A região possui um dos principais roteiros de mergulho do país, pois concentra diversidade de atrativos naturais como praias, ilhas rochosas e recifes artificiais submersos propícios para a prática da pesca esportiva e mergulho (DIAS-NETO e DORNELLES, 1996). Ainda, o turismo na área é intensamente praticado nos finais de semana principalmente no período do verão em que a população estimada em 120 mil habitantes recebe 500 mil pessoas dentre turistas e excursionistas (SETUR, 2018). Nesta região também há conflitos entre praticantes de pesca esportiva e mergulho, e pescadores artesanais (KNOX e TRIGUEIRO, 2014).

Pescadores artesanais possuem um conhecimento tradicional elaborado pela observação constante do ambiente em que vivem sendo compartilhado através de experiências do cotidiano (BEGOSSI, 2001). Este saber tradicional relacionado ao turismo é desvalorizado nas políticas públicas uma vez que não deriva do método científico (BEGOSSI, 2001). A Oceanografia Socioambiental envolve estudos a partir da interação do homem com o ambiente marinho por meio de métodos das Ciências Humanas e Sociais. Inserida no contexto social, cultural e ambiental essa área relaciona principalmente conflitos socioambientais na interface terra e mar (NARCHI et al., 2018).

Neste sentido, este estudo aborda a Oceanografia Socioambiental junto ao conhecimento de pescadores relacionado ao turismo de pesca esportiva e mergulho a fim de garantir o uso sustentável do espaço pelos envolvidos contribuindo na elaboração de políticas para valorizar tanto a pesca artesanal quanto o turismo sustentável. O objetivo deste estudo é descrever a percepção de pescadores artesanais que atuam na costa do município de Guarapari, ES, sudeste do Brasil em relação à interferência do turismo de pesca esportiva e mergulho sobre a pesca artesanal praticada na região. 


\section{MATERIAL E MÉTODOS}

Área de estudo

O município de Guarapari $\left(20^{\circ} 38^{\prime} \mathrm{S}-40^{\circ} 27^{\prime} \mathrm{O}\right)$ está localizado no estado do Espírito Santo, sudeste do Brasil a $50 \mathrm{~km}$ da capital Vitória. Essa região costeira apresenta um complexo insular, sendo as principais ilhas denominadas como Três Ilhas, Ilhas Rasas e Ilha Escalvada. Ainda, conta com o Recife Artificial Marinho (RAM) navio Victory 8-B e o navio naufragado acidentalmente Bellucia (Figura 1) que funcionam como importantes áreas para alimentação, reprodução e abrigo de espécies de valor comercial para a pesca artesanal, como também atrai turistas para a prática de pesca esportiva e mergulho (SANTOS et al., 2010; COSTA et al., 2014). Na região, a pesca artesanal é parte da cultura local em que está sediada a Colônia de Pescadores Z-3 e cadastrados aproximadamente 1.450 pescadores juntamente com 340 embarcações no Registro Geral da Atividade Pesqueira (RGP) (MPA, 2011).

FIGURA 1. LOCALIZAÇÃO DO MUNICÍPIO DE GUARAPARI, ILHAS COSTEIRAS, RECIFES SUBMERSOS, ÁREA USADA NA PESCA ARTESANAL E POR TURISTAS/EXCURSIONISTAS, NO ESTADO DO ESPÍRITO SANTO, SUDESTE DO BRASIL. LEGENDA: RAM NAVIO VICTORY 8-B - RECIFE ARTIFICIAL MARINHO

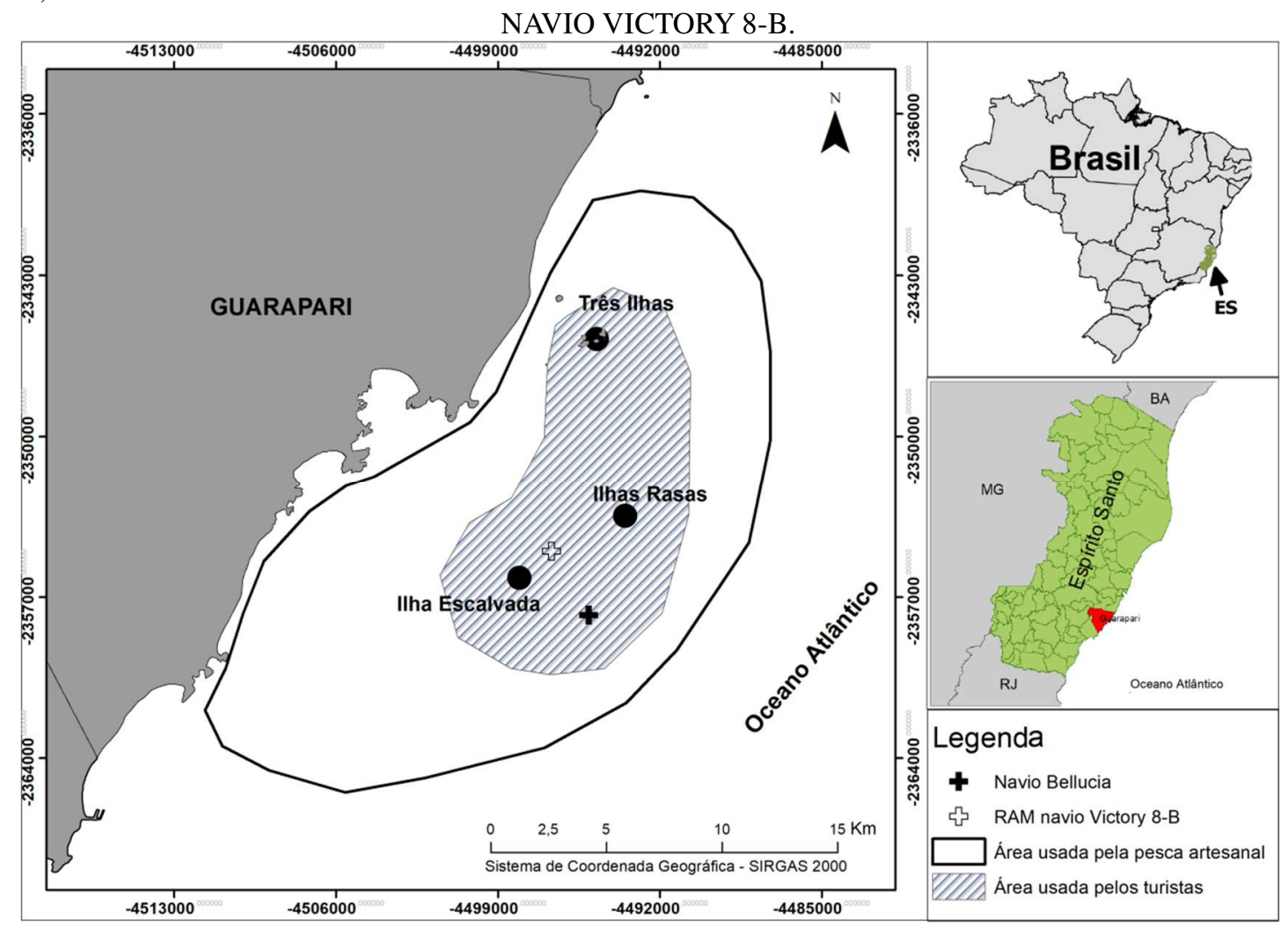

Fonte: Autor, 2021

\section{Procedimentos}

Entre os meses de dezembro 2017 e janeiro de 2018 foram realizadas entrevistas etnográficas individuais com 80 pescadores artesanais através de questionário semi-estruturado. Tal 
questionário continha perguntas abertas e fechadas, porém flexível para adicionar relatos caso necessário (SCHENSUL et al., 1999) (Box 1). O número de entrevistas é justificado pelo fato de que em estudos relacionados ao conhecimento tradicional o tamanho amostral ideal varia entre $30 \mathrm{e}$ 60, o que indica um tamanho de amostra adequado para este estudo (BERNARD, 2000). As observações participante e direta foram aplicadas para conhecer a rotina dos pescadores e as informações anotadas em um diário de campo (MALINOWSKI, 1978).

BOX 1. TÓPICOS DAS QUESTÕES DO QUESTIONÁRIO SEMIESTRUTURADO.

\begin{tabular}{|l|}
\hline 1. Aspectos sociais \\
1.1 Sexo \\
1.2 Idade \\
1.3 Experiência na pesca (em anos) \\
1.4 Escolaridade \\
2. Descrição da atividade de pesca \\
2.1 Duração da pesca \\
2.2 Horário de pescaria \\
2.3 Período do ano em que a pesca é realizada \\
2.4 Área de pesca \\
2.5 Características das embarcações \\
2.6 Artefatos \\
2.7 Espécies-alvo \\
3. Percepção sobre a pesca esportiva e o turismo de mergulho \\
3.1 Atividade(s) realizada(s) pelos pescadores durante o verão \\
3.2 Ocorrência de pesca esportiva na região \\
3.3 Interferência da pesca esportiva sobre a pesca
\end{tabular}

Esta pesquisa foi submetida à Plataforma Brasil (base brasileira unificada para registros de pesquisas envolvendo seres humanos) e aprovada pelo Comitê de ética (CAAE: 03219018.0.0000.5243), além de ter sido cadastrada no Sistema de Gestão Nacional do Patrimônio Genético e do Conhecimento Tradicional Associado (SISGEN). Cada entrevistado foi informado sobre os objetivos do estudo, e questionado se aceitava participar, bem como seu anonimato garantido (LIBRETT e PERRONE, 2010). O Termo de Anuência Prévia para realização deste 
estudo foi obtido junto ao presidente da Colônia de Pescadores Z-3, representante legal dessa categoria de trabalhadores na região (AZEVEDO, 2005).

Os entrevistados foram selecionados a partir dos seguintes critérios: 1) ser pescador artesanal cadastrado na Colônia de Pescadores Z-3; 2) ter a prática de pesca artesanal como principal fonte de renda e 3) atuar em área próxima ao RAM navio Victory 8-B. A escolha do primeiro entrevistado ocorreu através do auxílio do presidente da Colônia de Pescadores Z-3. A partir da segunda entrevista foi utilizado o método bola-de-neve que consiste na indicação de um possível entrevistado por pescadores que já participaram do estudo (BAILEY, 1982). Este método podia ser interrompido, sendo a partir daí utilizada a aleatoriedade por meio de encontros oportunísticos com os pescadores.

\section{Análise de dados}

As informações foram organizadas em categorias associadas às questões do questionário (BERNARD, 2000). Para comparar as informações contidas nos relatos foi utilizada a técnica de informação repetida em sincronia, na qual o mesmo questionário foi aplicado a todos os entrevistados em diferentes dias (OPDENAKKER, 2006). Para análise inicial foi aplicado o método de Triangulação a fim de cruzar as informações coletadas pelos diversos métodos e ferramentas utilizadas identificando semelhanças e discrepâncias nos dados (TEIS e TEIS, 2006). Ainda, a Análise de Discurso sobre os relatos foi aplicada a fim de compreender o contexto histórico e social dos pescadores, bem como os significados que envolve a cultura da pesca (ORLANDI, 2010). Os relatos foram quantificados e suas frequências percentuais foram descritas.

\section{RESULTADOS}

Todos os pescadores entrevistados $(n=80)$ são do sexo masculino com idade entre 27 e 77 anos, e até 60 anos de experiência na pesca artesanal (Tabela 1). O nível de escolaridade é baixo já que $85 \%(n=68)$ não completou o ensino fundamental; $10 \%(\mathrm{n}=8)$ concluiu o ensino médio; $3,75 \%$ $(\mathrm{n}=3)$ não responderam e apenas $1,25 \%(\mathrm{n}=1)$ concluiu o ensino superior. $\mathrm{O}$ tempo de autonomia no mar é de até 1 dia (24 horas) embarcado geralmente saindo para a pescaria às 02:00 horas da manhã com retorno às 18:00 horas. A pesca artesanal é praticada durante o ano todo por todos os entrevistados. 
TABELA 1. TEMPO DE PRÁTICA DOS PESCADORES ARTESANAIS DE GUARAPARI, ESTADO DO ESPÍRITO SANTO, SUDESTE DO BRASIL.

\begin{tabular}{lcc}
\hline Tempo na pesca & Número de relatos & \% \\
\hline $3-20$ anos & 28 & 35 \\
$21-40$ anos & 35 & 43,7 \\
$41-60$ anos & 17 & 21,3 \\
\hline Total & $\mathbf{8 0}$ & $\mathbf{1 0 0}$ \\
\hline
\end{tabular}

De acordo com os pescadores entrevistados a pesca artesanal é praticada principalmente na área de entorno das Ilhas Rasas, Ilha Escalvada, Três Ilhas; além do RAM Victory 8-B, o navio naufragado Bellucia e ao longo da costa do município de Guarapari. As embarcações são do tipo traineira de madeira variando de $5,5 \mathrm{~m}$ a $11 \mathrm{~m}$ de comprimento e o motor entre 10 e $140 \mathrm{HP}$. Os artefatos de pesca artesanal mais utilizados incluem linha $(\mathrm{n}=78 ; 79 \%)$ e rede de espera $(\mathrm{n}=16$; 17\%) (Tabela 2). Alguns pescadores utilizam mais de um artefato de pesca artesanal o que justifica o número de reposta $(\mathrm{n}=99)$ superior ao número de entrevistado $(\mathrm{n}=80)$. Dentre as espécies alvos preferenciais da pesca praticada na região foram citadas principalmente peixes ósseos das famílias Sciaenidae, Scombridae, Tetraodontidae, Coryphaenidae, Balistidae, Carangidae, Centropomidae, Gerreidae, Sparidae, Serranidae, Carcharhinidae, Lutjanidae, Pomatomidae, Pinguipedidae, Trichiuridae e Scombridae.

TABELA 2. ARTEFATOS UTILIZADOS NA PESCA ARTESANAL EM GUARAPARI, ESTADO DO ESPÍRITO SANTO, SUDESTE DO BRASIL DE ACORDO COM OS RELATOS DOS ENTREVISTADOS.

\begin{tabular}{lcc}
\multicolumn{2}{c}{ SANTO, SUDESTE DO BRASIL DE ACORDO COM OS RELATOS DOS ENTREVISTADOS. } \\
\hline Artefato & Número de relatos & $\mathbf{\%}$ \\
\hline Linha & 78 & 79 \\
Rede de espera & 16 & 2 \\
Arpão & 2 & 2 \\
Espinhel & 2 & $\mathbf{1 0 0}$ \\
\hline Total & $\mathbf{9 9}$ & 2 \\
\hline
\end{tabular}

Durante a estação de verão, 56 (70\%) pescadores atuam como guia de turismo informal na região por meio de passeios de barcos (Tabela 3). Trinta e três $(41,25 \%$ ) informaram que os turistas/excursionistas praticam pesca esportiva e mergulho durante estes passeios, já que a região apresenta atrativos naturais como praias, recifes submersos e ilhas rochosas. Na percepção dos pescadores artesanais $(n=37 ; 46,2 \%)$ este turismo interfere negativamente na atividade, pois há 
competição pelo pescado e interferência na comercialização do mesmo. Isso porque com a captura do pescado, o visitante deixa de comprar o produto do pescador. Em contrapartida, 21 (26,3\%) pescadores relataram que não há interferência, 13 (16,3\%) não souberam informar e nove (11,2\%) não responderam.

TABELA 3. ATIVIDADES SECUNDÁRIAS EXERCIDAS PELOS PESCADORES ARTESANAIS DURANTE A ESTAÇÃO DE VERÃO EM GUARAPARI, ESTADO DO ESPÍRITO SANTO, SUDESTE DO BRASIL DE ACORDO COM OS RELATOS DOS ENTREVISTADOS.

\begin{tabular}{lcc}
\hline Atividades & Número de Relatos & $\%$ \\
\hline Guia de turismo informal & 56 & 70 \\
Pesca artesanal & 20 & 25 \\
Porteiro & 2 & 2,5 \\
Não respondeu & 2 & 2,5 \\
\hline Total & $\mathbf{8 0}$ & $\mathbf{1 0 0}$ \\
\hline
\end{tabular}

\section{DISCUSSÃO}

No município de Guarapari a pesca artesanal é praticada principalmente por homens com baixo nível de escolaridade sendo este um cenário comum para outras áreas do estado do Espírito Santo (ES) e para a região sudeste do Brasil (MARTINS et al., 2009). A pouca formação técnica é comum entre os trabalhadores da pesca artesanal no país o que dificulta a busca por empregos com melhores salários e intensifica a dependência financeira dos pescadores pela atividade (OLIVEIRA et al., 2016). Por ser uma atividade cultural, a pesca artesanal é repassada entre membros familiares, sendo uma das principais atividades econômicas de comunidades litorâneas (OLIVEIRA et al., 2016). Esta herança cultural influencia na escolha da profissão fazendo com que os jovens sejam inseridos precocemente na pesca a fim de complementar a renda familiar o que dificulta a dedicação aos estudos (ABREU et al., 2017; PAES et al.,2018). Além disso, as dificuldades sociais, ambientais e econômicas levam ao desprestígio profissional e exclusão social da categoria (ABREU et al., 2017).

A pesca artesanal é uma atividade que tem sua origem no núcleo familiar e se contrasta com a pesca industrial em relação às técnicas e área utilizadas (OLIVEIRA et al., 2016). No município de Guarapari essa atividade é praticada durante todo o ano, ao longo da costa, principalmente na região que abarca as ilhas rochosas (Três Ilhas, Ilhas Rasas, Ilha Escalvada), o RAM Victory 8-B e o navio naufragado Bellucia. Esses locais apresentam habitat para inúmeras espécies que chama atenção de pescadores artesanais em busca de pescado para subsistência e 
comercialização (COSTA et al., 2014) e de praticantes da pesca esportiva e mergulho. As embarcações rústicas e de pequeno porte utilizadas na pesca artesanal impedem a navegação em áreas distantes do litoral e permitem o armazenamento e conservação do pescado em geladeiras e/ou isopores apenas por poucas horas (MARTINS et al., 2009).

No litoral de Guarapari os artefatos usados são semelhantes aos utilizados em outras áreas do estado do ES e da região sudeste do Brasil (MARTINS et al., 2009; MPA, 2011) sendo a predominância do uso da linha justificada devido ao fácil manuseio próximo às ilhas e fundo rochoso, característica local; ao baixo custo operacional; e por ser mais seletivo com menor descarte de material (MARTINS et al., 2009). Em geral, a pesca na região enquadra na constituição brasileira como predominante artesanal de pequena escala com uso de tecnologias menos intensivas (BRASIL, 2009).

O aumento da ocupação costeira e o livre acesso aos recursos pesqueiros tem aumentado ano após ano, porém os estoques pesqueiros estão diminuindo forçando os pescadores artesanais a abandonarem suas atividades em busca de outras áreas e/ou obterem fontes de renda em paralelo com a pesca (FITTON et al., 2016; CIDREIRA - NETO et al., 2019). Essa evasão do setor pesqueiro faz com que o pescador artesanal busque maior segurança financeira em atividades secundárias, sendo a principal a de guia de turismo informal (DIAS, 2006). Os entrevistados são considerados guias de turismo informal, pois não possuem o Cadastro dos Prestadores de Serviços Turísticos (CADASTUR) emitido por órgãos oficiais de turismo das unidades federativas cujo objetivo é promover a legalização dos prestadores de serviços turísticos no Brasil (CADASTUR, 2011).

No país, o Ministério do Turismo define na Instrução Normativa (IN) $N^{\circ} .27$, de 30 de janeiro de 2014 que guia de turismo consiste no "profissional que faz atividades de acompanhamento, orientação e transmissão de informações a pessoas ou grupos, em visitas, excursões urbanas, municipais, estaduais, interestaduais, internacionais ou especializadas”. Assim, a presença de um guia de turismo confere qualidade técnica, conhecimento, organização e segurança para melhor aproveitamento do roteiro (DIAS, 2006). No entanto, a informalidade do serviço por parte dos pescadores artesanais de Guarapari pode fornecer um serviço limitado ao turista/excursionista e consequentemente não agradar o usuário. Isto pode se tornar um problema para a gestão do turismo na região caso não ocorra uma capacitação destes atores locais. Ainda, podem ocorrer acidentes de navegação como naufrágio, encalhe, colisão, abalroação, explosão, incêndio, varação, arribada e alijamento que são frequentes devido a falta de fiscalização e 
segurança nas embarcações, acarretando na morte ou ferimentos grave de turistas/excursionistas, abandono de embarcação, dano material e encalhe (NORMAM - 09, Marinha do Brasil, 2003). Desta maneira, a atividade de turismo subaquático requer preparação de todo um plano de operação de mergulho (POM) baseado em planejamento cuidadoso a fim de garantir a integridade física dos envolvidos (NORMAM - 15, Marinha do Brasil, 2016).

Belezas cênicas naturais atraem turistas para a prática da pesca esportiva e mergulho que contratam serviços não apenas de empresas de turismo da região, mas também de pescadores que devido à informalidade oferecem serviços por preços mais baixos (SOUZA, 2014). De acordo com o NORMAM (Normas da Autoridade Marítima), às embarcações de pesca de pequeno porte não é exigido a apresentação de documentação detalhada, em que a maioria é construída sem um projeto e/ou acompanhamento técnico especializado sendo baseado nos conhecimentos técnicos dos construtores artesanais (NORMAM - 01, Marinha do Brasil, 2012). Entretanto, as embarcações utilizadas pelos pescadores neste turismo informal são precárias devido à falta de equipamentos e acessórios de segurança necessários para a navegação de qualidade o que coloca em risco a vida dos embarcados (BRASIL, 2010).

Apesar dos pescadores artesanais não oferecerem aparato tecnológico para este tipo de turismo, possuem o conhecimento mais detalhado sobre as espécies e os melhores locais para a prática da pesca esportiva e mergulho. Tal conhecimento é devido sua experiência com o ambiente, sendo esta a característica que atrai o visitante independente da qualidade da embarcação. Desta forma, a expansão do turismo de pesca esportiva e mergulho provoca alterações na vida das comunidades pesqueiras que vislumbram neste ramo uma esperança de ascensão econômica. Porém, estas comunidades não estão capacitadas tecnicamente para atuarem neste setor, com isso são obrigadas a oferecerem um preço mais barato pelo serviço se tornando excluídos de seus próprios espaços (SOUZA, 2014). Uma alternativa para que os pescadores artesanais possam continuar na condução de grupos, mas dentro da legalidade e obterem a valorização da atividade, seria a atuação conjunta com condutores de visitantes legalizados (de acordo com a Instrução Normativa $N^{\circ} .27$, de 30 de janeiro de 2014 do Ministério do Turismo). Ainda, seria importante o estabelecimento de parcerias com empresas de turismo, iates clubes, Marinha do Brasil e Organizações Não Governamentais (ONG’s). Outra alternativa seria o poder público atuar na formação dos pescadores artesanais como guias, de modo a formalizá-los.

Atividade de pesca esportiva e mergulho geralmente é realizada por mergulhadores recreativos de empresas de turismo que atuam de forma legal, e por pescadores artesanais e 
turistas/excursionistas de forma ilegal (SEAMAN e SPRAGUE, 1991). Atualmente, as atividades de lazer movimentam um número expressivo de visitantes em todo o litoral de Guarapari, e a pesca esportiva, o mergulho e a pesca artesanal ocorrem sem fiscalização da captura de pescado estabelecido legalmente (JULIO et al., 2016). Entretanto, alguns usufruem da carência de fiscalização para praticar a pesca com uso de arpão e utensílios de mergulho autônomo (SANTOS et al., 2010). Como consequência há o surgimento de conflitos por território e recurso pesqueiro entre os envolvidos nestas atividades sendo os embates entre pesca artesanal e turismo os mais frequentemente descritos (CASTRO, 2000).

Geralmente, comunidades pesqueiras são favoráveis à visitação em seus territórios de pesca, porém a exploração desordenada pelo turismo descaracteriza e diminui a sustentabilidade das populações tradicionais (SANTOS e ARANTES, 2010). Em Guarapari, a interferência do turismo de pesca esportiva e mergulho é percebida de maneira negativa pelos pescadores artesanais justamente pela competição de uso de área e de recursos pesqueiros. Apesar dos pescadores obterem renda extra com o aluguel das embarcações para os passeios, o conflito gerado sobrepõe esta percepção. Visitantes sem autorização legal utilizam artefatos modernos e com maior capacidade de captura competindo com pescadores artesanais que utilizam artefatos mais simples surgindo daí um cenário de competição (SANTOS e ARANTES, 2010). Desta maneira, para Guarapari é necessária a elaboração de um planejamento costeiro que envolva tanto a comunidade residente quanto visitantes a fim de garantir a manutenção da cultura pesqueira local e qualidade ambiental.

Uma etapa importante de um planejamento costeiro é compreender que em comunidades pesqueiras as formas de apropriação do espaço são definidas a partir da organização cultural por meio de relações sociais (BECKER, 2010). Desta maneira, regras e/ou acordos formais podem ajudar na solução de conflitos entre pescadores artesanais e turistas/excursionistas (BEGOSSI, 2001). As práticas locais devem ser identificadas e incorporadas às iniciativas de gestão dos recursos pesqueiros e a participação efetiva da comunidade local no processo de planejamento e na tomada de decisão (SEABRA, 2007). Portanto é necessária uma co-gestão do uso do espaço para regular as atividades de pesca esportiva e mergulho, além de estratégias de fiscalização para manutenção de qualidade de vida local e sustentabilidade do ambiente (SEABRA, 2007). A seguir são propostas medidas de gestão a serem realizadas entre os envolvidos (poder público, moradores, turistas, excursionistas e empresas que atuam no ramo turístico) a fim de diminuir o conflito de uso da área (Quadro 1). 
QUADRO 1. PROPOSTAS DE MEDIDAS DE GESTÃO A SEREM REALIZADAS JUNTO AOS STAKEHOLDERS (PODER PÚBLICO, SOCIEDADE CIVIL E EMPRESAS DE TURISMO) A FIM DE DIMINUIR O CONFLITO DE USO DA ÁREA ENTRE PESCADORES ARTESANAIS E TURISTAS/EXCURSIONISTAS.

\section{Ações}

1) Promoção de diálogo entre atores locais e órgãos públicos a fim de construir a co-gestão da pesca artesanal.

2) Desenvolvimento de marketing social dos benefícios do turismo de pesca esportiva e mergulho. Essas informações podem ser transmitidas informalmente/oralmente entre os pescadores.

3) Promoção de programas de educação conjuntas com a academia, pescadores e empresas de turismo sobre a legislação da pesca e prática de turismo de pesca esportiva e mergulho. Nesta ação deve ser usado vocabulário local, para permitir ampla compreensão por parte dos pescadores e turistas.

4) Promoção de rede de diálogo entre a autoridade pública, gestores locais, comunidade de pescadores e empresas de turismo para identificar os problemas causados pela prática de turismo de pesca esportiva e mergulho irregulares.

5) Elaboração de ações conjuntas entre academia, pescadores e poder público a fim de garantir a manutenção da pesca artesanal e a sustentabilidade da prática do turismo de pesca esportiva e mergulho.

\section{Atores}

Colônia de Pescadores; Instituições de Ensino e Pesquisa e órgãos fiscalizadores da área ambiental e setor turístico sediados na região.

Organizações não governamentais; Instituições de Ensino e Pesquisa sediadas na região; setor turístico e Colônia de Pescadores.

Organizações não governamentais; Instituições de Ensino e Pesquisa e setor turístico sediadas na região.

Organizações não governamentais; Instituições de Ensino e Pesquisa e setor turístico, órgãos fiscalizadores da área ambiental e setor turístico sediados na região.

Organizações não governamentais; Colônia de Pescadores; Instituições de Ensino e Pesquisa sediadas na região. 
6) Divulgação de resultados de pesquisas científicas relacionadas às questões pesqueiras, sociais, culturais, econômicas, e turismo de pesca esportiva e mergulho junto às comunidades pesqueiras.

7) Intensificação na fiscalização por parte de órgãos ambientais a fim de evitar a sobrepesca e prática de turismo de pesca esportiva e mergulho irregulares.

8) Delimitação de área destinadas apenas à pesca artesanal e prática de turismo de pesca esportiva e mergulho.

9) Criação de um reservatório para cultivo de iscas para pesca, a fim de incentivar o desenvolvimento de novos negócios nas comunidades de pescadores.

10) Organização de passeios turísticos dentro da comunidade pesqueira para que o turista/excursionista possa vivenciar a rotina dos envolvidos na pesca artesanal, desde o desembarque pesqueiro até limpeza do pescado em que os próprios stakeholders envolvidos com a pesca seriam os 'atores' desta atividade.

\author{
Organizações não governamentais; Instituições de \\ Ensino e Pesquisa sediadas na região. \\ Órgãos fiscalizadores da área ambiental. \\ Instituições de Ensino e Pesquisa e setor turístico na \\ região, órgãos gestores ambientais e Colônia de \\ Pescadores. \\ Organizações não governamentais; Colônia de \\ Pescadores, Instituições de Ensino e Pesquisa e \\ Empresas de Artefatos de Pesca sediadas na região. \\ Organizações não governamentais; Colônia de \\ Pescadores e setor turístico da região.
}




\section{CONCLUSÃO}

A atividade pesqueira artesanal em Guarapari, ES, sudeste do Brasil, é praticada em toda costa do município, principalmente em locais próximos às ilhas rochosas e estruturas recifais artificiais instaladas na região. Sobrepondo este território de pesca há durante a estação do verão (meses de dezembro a fevereiro) a prática do turismo de pesca esportiva e mergulho que utiliza tanto a área quando os recursos pesqueiros; além de interferir na comercialização da pesca artesanal. Na percepção dos pescadores artesanais há interferência negativa deste ramo turístico sobre a prática da pesca local, pois ocorre de forma desordenada sem obedecer a legislação. Contudo essa situação de desordem e conflito pode ser modificada mediante a elaboração de ações de co-gestão a fim de garantir a manutenção da cultura local da pesca artesanal, bem como dos recursos, permitindo a prática sustentável do turismo e a qualidade das comunidades pesqueiras tradicionais.

\section{AGRADECIMENTO}

Agradecemos ao presidente da Colônia de Pescadores Z-3 e aos pescadores de Guarapari por sua cooperação. Agradecemos a Raquel da Silva Paes pelo apoio durante a etapa de campo. À Coordenação de Aperfeiçoamento de Pessoal de Nível Superior - Brasil (CAPES) - Código de financiamento 001 para concessão de mestrado; ao Conselho Nacional de Desenvolvimento Científico e Tecnológico (CNPq 400053/2016-0) e à Fundação Carlos Chagas Filho de Amparo em Pesquisa do Estado do Rio de Janeiro (FAPERJ E-26/203.202/2016 e E-26/202.789/2019) pelo apoio financeiro.

\section{REFERÊNCIAS}

ABREU, J.S.; DOMIT, C.; ZAPPES, C.A. Is there dialogue between researchers and traditional Community members? The importance of integration between traditional knowledge and scientific knowledge to coastal management. Ocean Coast. Manag., v. 141, p. 10-19, 2017.

AZEVEDO, C.M.A. A regulamentação do acesso aos recursos genéticos e aos conhecimentos tradicionais associados no Brasil. São Paulo: Biota Neotrop, v. 5, n.1, p.19-27, 2005.

BAILEY, K.D. Methods of Social Research. 2ed. New York: McMillan Publishers. The Free Press, 1982.

BECKER, B. K. Novas territorialidades na Amazônia: desafio às políticas públicas. Bol. Mus. Para. Emílio Goeldi, ser. Ciências Humanas, v. 5, n. 1, p. 17-23, 2010. 
BEGOSSI, A. Cooperative and Territorial Resources: Brazilian Artisanal Fisheries. Chapter 5. In: BURGER J. (Ed). Protecting the commons: a framework for resource management in the Americas. 2001.

BERNARD, H. R. Social research methods: qualitative and quantitative approaches. California: Sage Publications, Thousand Oaks, 2000. 412p.

BRASIL. Lei Federal $\mathbf{n}^{\circ} 11.959$ de 29 de Junho de 2009. Dispõe sobre a Política Nacional de Desenvolvimento Sustentável da Aquicultura e da Pesca, regula as atividades pesqueiras, revoga a Lei no 7.679, de 23 de novembro de 1988, e dispositivos do Decreto-Lei $n^{\circ} 221$, de 28 de fevereiro de 1967, e dá outras providências. Diário Oficial da República Federativa do Brasil, Brasília, 2009,

BRASIL. Ministério do Turismo. Turismo Náutico: orientações básicas. / Ministério do Turismo, Secretaria Nacional de Políticas de Turismo, Departamento de Estruturação, Articulação e Ordenamento Turístico, Coordenação Geral de Segmentação. 3 ed. Brasília: Ministério do Turismo, 2010.

CADASTUR. Cadastro dos Prestadores de Serviços Turísticos, 2011. Disponível em <http://www.turismo.gov.br/sites/default/turismo/o_ministerio/publicacoes/downloads_publicacoes/ Cadastur.pdf $>$ Acessado em 27 de jun. de 2019.

CASTRO, F. Fishing accords. The political Ecology of Fishing Intensification in the Amazon. Doctoral Thesis. Center of the Study of Institutions, Population and Environmental Change, Indiana University, Indiana, 2000.

CIDREIRA-NETO, I.R.G.; FRAGOSO, M.L.B.; RODRIGUES, G.G. Pesca artesanal do marisco no litoral paraibano: relações socioambientais e tecnologias sociais. Revista de Geografia. Recife, v. 36, n. 1, p. 97-109, 2019

COSTA, E.S.; ANDRADE, R.R.; JUNIOR, L.B.; GAIGHER, L.P.; OLIVEIRA, C.M.S.; JUNIOR, C. D.; NETO, R. R. Controls on Temporal and Spatial Variation of Nutrients in a Tropical Marine Artificial Reef: The Case of the Victory 8B on the Southeastern Brazilian Coast. Rev. Virtual Quim., v. 6, n. 4 p. 834-843, 2014.

DIAS-NETO, J. S.; DORNELLES, L. C. C. Diagnóstico da pesca marítima do Brasil. Brasília: IBAMA, 1996.164p.

DIAS, R. Turismo e patrimônio cultural: Recursos que acompanham o crescimento das cidades. SP: Saraiva, 2006. 257p.

FAUKENBERRY, L. V. COGGESHALL, J.; BACKMAN, K.; BACKMAN, S A culture of servitude: the impact of tourism and development on South Carolina's coast. Hum. Organ. US, v.59, n.1, p. 86-95, 2000.

FITTON, J. M.; HANSON, J. D. \& RENNIE, A. F. A national coastal erosion susceptibility model for Scotland. Ocean Coast. Manag., v. 132, p. 80-89, 2016.

IBGE. Instituto Brasileiro de Geografia e Estatística, 2018. Disponível em < https://cidades.ibge.gov.br/brasil/es/guarapari/panorama> Acessado em 22 de jun. de 2019.

IOTMG. Inventário da Oferta Turística do Município de Guarapari, 2005. Disponível em < https://observatoriodoturismo.es.gov.br/Media/observatorio/Pesquisas/Inventarios\%20Municipais/G uarapari.pdf> Acessado em 25 de jun. de 2019.

\begin{tabular}{lll}
\hline Abreu, Oliveira e Zappes, 2021 & 344
\end{tabular}


IRTS. International Recommendations for Tourism Statistics, 2008. Disponível < https://unstats.un.org/unsd/publication/Seriesm/SeriesM_83rev1e.pdf> Acessado em 16 de jun. de 2019.

JULIO, T.S.; GOMES, V.A.P.; FREITAS, R.R. Índice de Potencialidade Socioeconômica, Produtiva e Ambiental da pesca marinha e estuarina na região sul do Espírito Santo (IPSPA-Sul). Espacios, v. 37, n.31, 2016.

KNOX, W.; TRIGUEIRO, A. A pesca artesanal, conflitos e novas configurações. REDD, Araraquara,v. 8, n.2, p. 1-18, 2014.

LIBRETT, M.; PERRONE, D. Apples and oranges: ethnography and the IRB. Qualitative Research,v.10, p. 729-774, 2010.

MARINHA DO BRASIL. NORMAM 15/DPC: Normas da Autoridade Marítima para atividades subaquáticas. Rio de Janeiro: Marinha do Brasil, 2016.

MARINHA DO BRASIL. NOMAM 01: Normas da Autoridade Marítima para embarcações empregadas na navegação de mar aberto. Rio de Janeiro: Marinha do Brasil, 2012.

MARINHA DO BRASIL. NORMAM 09/DPC: Normas da Autoridade Marítima para inquéritos administrativo sobre acidentes e fatos da navegação (IAFN) e para a investigação de segurança dos acidentes e incidentes marítimos (ISAIM). Rio de Janeiro: Marinha do Brasil, 2003.

MALINOWSKI, B.K. Os pensadores: Argonautas do Pacífico Ocidental: Um relato do empreendimento e da aventura dos nativos nos Arquipélagos da Nova Guiné Melanésia. 2 ed. Abril Cultural, São Paulo, 1978. 424p.

MARTINS, H.H.T.S. Metodologia Qualitativa de Pesquisa. Educ. Pesqui, v. 30, p.289-300, 2004

MARTINS, A.S.; SANTOS, L.B.; PIZETTA, G.T.; MONJARDIM, C.; DOXSEY, J,R. Interdisciplinary assessment of the status quo of the marine fishery systems in the state of Espirito Santo, Brazil, using Rapfish. J. Appl. Ichthyol., v.25, p. 269-276, 2009.

MILLER, M. L. The rise of coastal and marine tourism. Ocean Coast. Manag. v.20, p.181-199, 1993.

MINISTÉRIO DO TURISMO/BRASIL. Instrução Normativa n. 27, de 30 de Janeiro de 2014. Estabelece requisitos e critérios para o exercício da atividade de Guia de Turismo e dá outras providências. Ministério do Turismo, Brasília, 2014.

MPA. Boletim Estatístico da Pesca e Aquicultura. Ministério da Pesca e Aquicultura, Brasília, 2011.

NARCHI, N.E.; CORIÑO, M.; MESA-JURADO, M.A.; ESPINOZA-TENORIO, A.; OLIVOSORTIZ, A.; CAPISTRÁN, M.M.E.; MORTEO, E.; OCHOA, Y.; BEITL, C.; MARTÍNEZ, T.; CERVANTES, O.; NAVA, H.H.; SPALDING, A.; GRACE-MCCASKEY, C.; CORONA, N.; MOURA, G.G.M. "El CoLaboratorio de Oceanografía Social: espacio plural para la conservación integral de los mares y las sociedades costeras". Soc. Ambient., v.18, p.285-301, 2018.

OLIVEIRA, P.C.; DI BENEDITTO, A.P.M.; BULHÕES, E.M.R. ; ZAPPES, C. A. Artisanal fishery versus port activity in southern Brazil. Ocean Coast. Manag., v. 129, p. 49-57, 2016. 
OPDENAKKER, R. Advantages and disadvantages of four interview techniques in qualitative research, 2000. Disponível em <http://nbn-resolving.de/urn:nbn:de:0114-fqs0604118S > Acessado em 23 de jun. de 2019.

ORLANDI, E.P. Análise do discurso. Princípios e Procedimentos. Campinas: Pontes Editores. 2010. 101p.

PAES, R. S.; ZAPPES, C. A. Cadeia produtiva dos cultivos da agricultura familiar do $5^{\circ}$ distrito de São João da Barra, norte do Rio de Janeiro. Revista de Geografia (Recife), v. 35, p. 376-387, 2018.

ROWE, R.Y.G.; SANTOS, G.E.O. Turismo de mergulho: análise do comportamento de viagem dos mergulhadores brasileiros. Caderno Virtual de Turismo, Rio de Janeiro, v.16, n. 3, p.61-75, 2016.

SANTOS, D.H.C; CUNHA, M.G.G.S.; AMANCIO,F.C.; PASSVANTE, J.Z.O. Recifes Artificiais, Mergulho e Pesca Artesanal: Alguns Aspectos do Conflito na Costa de Pernambuco - Brasil. Rev. Gest. Cost. Integ, v. 10, p.7-22, 2010.

SANTOS, R. J.; ARANTES, E. M. Turismo e dinâmica cultural em uma comunidade de pescadores artesanais: o caso do farol de Santa Marta em Laguna (SC). RETUR, v. 4, n.1, p.5-23, 2010.

SCHENSUL, S.L.; SCHENSUL, J.J.; LECOMPTE, M.D. Essential Ethnographic Methods: Observations, Interviews and Questionnaires. Altamira Press, Walnut Creek, 1999. 344p.

SEABRA, G.F. Turismo sertanejo. João Pessoa: UFPB, 2007. 174p.

SEAMAN, W.JR.; SPRAGUE, L.M. Artificial Habitats for Marine and Freshwater Fisheries. Academic Press. San Diego, EUA, 1991. 258p.

SETUR. Secretária de Turismo do Espírito Santo, 2018. Disponível em < https://observatoriodoturismo.es.gov.br/Media/observatorio/Pesquisas/Telefonia\%20M\%C3\%B3vel /Guarapari_JAN17.pdf> Acessado em 22 de jun. de 2019.

SOUZA, M.R. Etnoconhecimento caiçara e uso de recursos pesqueiros por pescadores artesanais e esportivos no Vale do Ribeira. Dissertação de Mestrado. Universidade de São Paulo, Piracicaba, 2014.

TEIS, M.A.; TEIS, D.T. A Abordagem Qualitativa: A Leitura no Campo de Pesquisa. A abordagem qualitativa: a leitura no campo de pesquisa. BOCC, v. 1, p. 1, 2006.

WORLD TOURISM ORGANIZATION. Tourism: 2020 vision: global forecast. madrid: UNWTo, 2007. 